\title{
Conditioning of the Graphite Bumper Limiter for \\ Enhanced Confinement Discharges in TETR
}

\author{
H.F. Dylla, P.H. LaMarche, M. Ulrickson, R.J. Goldston, \\ D.B. Heifetz, K.W. Hill, and A. T. Ramsey \\ Princeron Plasma Physics Laboratory
}

$$
\text { P.0. Box 451, }
$$

Princeton, NJ 08544

PPPL --2448

DE87 013199

\section{Abstract}

A strong pumpialg effect has been observed with plasma operation on the toroidal graphite bumper limiter on TFTR. The pumping effect was induced by conditioning the limiter with a short series (10-20) of low density deuteriumor helium-initiated discharges. The densicy decay constant $\left(\tau_{p}{ }^{*}\right.$ ) for gasfueled ohmic discharges was reduced from $\tau_{p}{ }^{*}>10 \mathrm{~s}$ before conditioning to a minimum value of $\tau_{p}{ }^{*}=0.15 \mathrm{~s}$ after conditioning, corresponding to a reduetion in the global recycling coefficient from $~ 100 \%$ to less than 50\% c Coincident with the low recycling conditions, low current neutral-beam-fueled discharges show global energy confinement times which are enhanced by a factor of two over results with an unconditioned limiter. Two models are proposed for the observed pumping effects: (1) a depletion model based on pumping of hydrogenic species in the near-surface region of the limiter after depletion of the normally saturated surface layer by (carbon and helium) ion-induced desorption: and (2) a codeposition model based on pumping of hydrogenic species in carbon films gputtered from the limiter by the conditioning process.

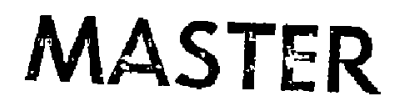

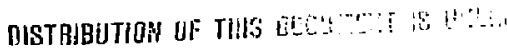




\subsection{Introduction}

TFTR has been operating since Seprember 1985 with a toroidal bumper limiter which covers a $120^{\circ}$ poloidal segment of the inner wall. The bumper limiter is constructed of POCOR AXF-5Q graphite tiles, totals $2000 \mathrm{~kg}$ in mass, and presents a geometric surface area of approximately $22 \mathrm{~m}^{2}$ to the torus vacuum [1]. The density of the graphite is about $1.8 \mathrm{~g} / \mathrm{cm}^{3}$, which is approximately $30 \%$ less than the maximun density of graphite. Recent laboratory measurements on the graphice tile material, including surface area measurements using rare gas adsorption [2] and hydrogen isotope retention measurements [3-7], indicate that the bulk porosicy of the graphite is well connected to the surface. This property is expected to affect both the solubility and diffusivity of sorbed hydrogenic and impurity (primarily oxygen) species in the graphite, and hence affect the hydrogenic and impurity recycling properties of the limiter. We have developed new conditioning techniques for the bumper limiter for the purpose of reducing the impurity influx and for modifying the hydrogenic recycling properties.

For reducing impurities a new conditioning technique $[B]$, dusbed "distuptive discharge cleaning" (DDC), has been developed which involves intentionally distupting high power discharges against the bumper limiter. This procedure enhances water desorption by heating the bumper limiter to high surface temperatures $\left(>1000^{\circ} \mathrm{C}\right)$. The standard bakeout temperature of TETR $\left(150^{\circ} \mathrm{C}\right)$ and the surface heating due to heat deposition from typical ohmically heated discharges $\left(\leq 60^{\circ} \mathrm{C}\right)$ are insufficient to degas the large quantities of $\mathrm{H}_{2} \mathrm{O}$ that are sorbed by the AXF-5Q graphite following atmospheric exposure [9].

For modifying the hydrogenic recycling properties we have found that the application of a short series (10-20) of low density, helium- or deuteriuminitiated ohmic discharges reduces the recycling coefficient of the graphite 
limiter leading to lawer edge neutral densities. In subsequent neutral-beamfueled discharges these modified edge conditions have regulted in a rore peaked plasma density profile, and have led to energy confinement paramerers which are enhanced by a factor of two over previously attained values [i0-12].

\subsection{Observed Change in Recycling}

Recycling can be messured using the characteristic electron density decay constant, $\tau_{p}{ }^{*}$, defined by a plasma density decay factor of exp $\left(-t / \tau_{p}{ }^{*}\right)$ in the presence of no external sources, and a global electron recycling coefficient,

$$
\mathbf{R}=1-\tau_{\mathrm{P}} / \tau_{\mathrm{p}}^{*}
$$

which is a measure of the enhancement of $\tau_{p}^{*}$ over the globally-averaged core particle confinement time, "T $p$. If $\tau_{p}{ }^{*}$ is measured immediately after gas fueling is turned off, the calculated $R$ may be assumed to be the same fot both the electrons and the fueling gas.

Recycling conditions in TFTR illustrated in Eig. la were typical of all TFTR plasma operations on the moveable limiter, and were also characteristic of bumper limiter operations prior to the application of the low density conditioning discharges. In this ohmic discharge (Fig. Ia) the temporal response of the midplane line-averaged plasma density is compared to the gagfueling rate. Gas input was usually required only during the density (and current) rise portion of the discharge. During the steady-state portion of the discharge, the gas input dropped to zero and the density was maintained at a slowly decaying level by recycling. The density decay constant, $\tau_{p}^{*}$, measured after turning off the gas input, was greater than $10 \mathrm{~g}$. 
Figure lb shows the change in recycling conditions observed after an initial conditioning of the bumper limiter with a series of ten, low densicy, $0,8 \mathrm{MA}$, He dischargeg. Gas input is required to maintain plasma densities above the minimal density, and when the gas input is intentionally terminated, the densicy decays with a time constant of $\tau_{p}^{*}=2.0 \mathrm{~g}$. A global particle confinement time of $\tau_{p}=0.1 \mathrm{~s}$ was obtained from $\mathrm{Da}$ emission and Langmuir probe measurements [13]. For the case shown in Fig. 1a, the value of $R$ is greater than 99\%. After the initial use of He condicioning, shown in Fig. lb, the recycling coefficient falls to $96 \%$. Figure lc shows the case for the lowest recycling observed, i.e., after extensive conditioning of the bumper limiter using this low density discharge technique. The density decay constant was determined by the density decay to a baseline density following a $100 \mathrm{~ms}$ deuterium gas pulse during a $0.8 \mathrm{MA}$ discharge (Fig. 1d). In this case the value of $T_{p}=$ is $0.15 \mathrm{~s}$, corresponding to a recycling coefficient of $R=0.3 \pm 0.2$.

\subsection{Comparison of Conditioning Sequences}

Decreased recycling from the bumper limiter has been observed for several types of low density conditioning sequences, in addition to the short $0.8 \mathrm{MA}$ He sequence described above. Having observed the effect with the initial use of He discharges, we undertook a more systematic investigation of the change in recycling conditions with extended exposure to low density discharges fueled by the or $D_{2}$ at varying plasma currents.

Figure 2 shows the shet-to-shot evolution of the minimum plasma density achieved in a series $0.8 \mathrm{MA} \mathrm{D}^{+}$conditioning discharges. The first sequence with $D^{+}$discharges shows an initial rapid drop in plasma density aiter the first five discharges; but then during the remainder of this and two furcher 
10-shot sequences, the density drop is less significant. Between the conditioning sequences, a short series of neutral-beam-injected (NBI) discharges were interspersed to test the effect of the conditioning on beam fueling.

Following the $\mathrm{D}^{+}$conditioning sequence, $\mathrm{He}^{++}$conditioning sequences with plasma currents of $0.8 \mathrm{MA}$ and $1.4 \mathrm{MA}$ were applied as shown in Figs. $3 \mathrm{a}$ and $3 \mathrm{~b}$, respectively. In contrast to the $\mathrm{D}^{+}$sequences, the $\mathrm{He}^{++}$sequences show a steady trend to lower plasma densities with increasing shot number. The lower densitieg achieved in the $\mathrm{He}^{++}$discharges resulted in densities in subsequent $0.8 \mathrm{MA} \mathrm{D}^{+}$digcharges which were below the apparent low density limit shown in Fig. 2. Figure 4 shows an expanded data base of the density vs. discharge number which spans a 1000-shot interval covering the initial $0.8 \mathrm{MA} \mathrm{D}^{+}$ conditioning sequence (Fiz. 2) followed by the $0.8 \mathrm{MA}, 1.4 \mathrm{MA}$ (Fig. 3) and 1.8 . MA (not shown) He ${ }^{++}$conditioning sequences: The density fell from $0.87 \times 10^{19} \mathrm{~m}^{-3}$ to $0.54 \times 10^{19} \mathrm{~m}^{-3}$ during this interval, and there is some indication that the minimum actainable density decreases with the current of the He ${ }^{++}$conditioning discharges. According to spectroscopic analysis of these low density discharges (both He and $D_{2}$ initiated), the dominant impurity is carbon and the measured values of $z_{\text {eff }}$ are equal to 6 within the estimated error $( \pm 15 \%)$ of the measurements $[14,15]$. Metals are estimated to contribute a value of $0.6 \pm B:\left\{\right.$ to $z_{\text {eff }}$; thus a $z_{\text {eff }}$ of 6 does not imply a pure carbon discharge or a total absence of deuterium.

The effectiveness of the conditioning discharges for degassing the Iimiter of deuterium is shown in Fig. 5, where the Da emission line brightness, which is proportional to the $D$ influx, decreases by a factor of 20 during this sequence. The cause of the two different decay constants ( $r$ ) observed in the decrement of Da emission with shot number is unknown. 
Variations in the decay constant have been observed during other conditioning sequences, possibly indicating that the time dependence of the deuterium degassing process depends on the initial deuterium retention conditions of the limiter.

The effect of the conditioning sequences on the recycling behavior of gas- and neutral-beam-fueled discharges is shown in Figs. 6, 8-10. Figure 6 shows the evolution of the density decay congtant $\left(\tau_{p}^{*}\right)$ over a span of 100 discharges, which includes the conditioning sequence shown in Figs. 2 and 3. These measurements were obtainec during fiducial discharges which were interspersed within the conditioning sequence. The fiducial discharges were programmed to a density of $\bar{n}_{e}=1.25 \times 10^{19} \mathrm{~m}^{-3}$, followed by a programmed interruption of the deuterium gas input at $2.0 \mathrm{~s}$ to allow the density to decay to the recycling limit. We assume here that the measured plasma density decay constant, $\tau_{p}{ }^{*}$, is representative of the decay in deuteron density, since the $\tau_{p}^{*}$ measurement follows the termination of deuterium gas injection. Over this discharge sequence the data in Fig. 6 show that $\tau_{p}$ " decreased from an initial value of $1.2 \mathrm{~s}$ to a minimurn value of $0.29 \mathrm{~s}$.

The corresponding change in the global recycling coefficient, $R$, was determined by golving

$$
\frac{d N}{d t}=\dot{N}_{R}-\frac{N}{\tau_{P}}
$$

for $\tau_{p}$ and Eq. (1) for $R$. The total deuterium ion population, $N$, inside the last closed flux surface at $r=0.8$ m was determined from measurements of $\bar{n}_{e}$ (assuming a parabolic profile) and $z_{\text {eff }}$. The rate $\dot{N}_{R}$ at which recycling neutrals reionized within $\zeta=0.8$ mas estimated from Do smission measurements from four detectors viewing the inner limiter. A two-dimensional 
simulation was made of the neutral particle transport using the DEGAS code [16] to correct the Da signals to include only contributions from neutral atoms and molecules ionized within $r=0.8 \mathrm{~m}$. (Toraidal variations in the Da signal were measured to be of the order of $\pm 10 \%$ and, therefore, were ignored.) The cortected Da signals were then multiplied by ratios of ionizations per Da photon calculated from the same simulation to compute $\hat{\mathbb{N}}_{\mathrm{R}}$.

Using the computed value of $\tau_{p}=0.14 \pm 0.04 \mathrm{~s}$ for this plasma current and density (Fig. 7), we calculated that the drap in $\tau_{p}{ }^{*}$ over the conditioning sequenc: shown in Figs. 2 and 3 indicates a drop in global recycling from $R \cong$ 0.9 to $\mathbb{R}=0.50 \pm 0.15$.

Further evidence of reduced recycling as a result of the bumper 1 imiter conditioning comes from edge neutral presgure and edge neutral flux (from Da emission) measurements. Figure 8 shows the observed drop in edge neutral pressure [17] and Da emission for the conditioning sequence shown in Figs. 2 and 3. The measurements were made at the torus outer midplane during the plasma density flateau $(t=2.0 \mathrm{~s})$ of fiducial discharges. A significant drop (a factor of $\sim 15$ for the edge pressure and a factor of -25 for Da) is evident as a result of the 1 imiter conditioning.

The effect of reduced recycling is illustrated by the time variation of che edge neutral pressure, plasma density, and reciuired gas input for gasfueled (fiducial) discharges in Fig, 9 and neutral-beam-fueled discharges in Fig. 10. The data in Figs. 9 and 10 are taken from discharges occurring during the beginning and end of the conditioning sequence shown in Figs. 2 and 3 to illustiate the changes from high recycling $(R=1)$ to low recycling conditions $(R=0.5)$.

The observed decrease in recycling after limiter conditionjing is not a permsnent effect. The recycling coefficient can be increased by exposure of 
the limiter to high density discharges.: This gas-loading effect has been quantified by exposing a conditioned limiter to a series of nominally identical ohmic discharges at the fiducial density $\left(\bar{n}_{\mathrm{e}}=1.25 \times 10^{19} \mathrm{~m}^{-3}\right)$. Starting from conditions where $R=0.5$, exposure to ten fiducial discharges increased the recycling coefficient to $R=0.8$. Over this same discharge sequence the gas input required to fiel the discharge decreased from 40 torrlicers to an asymptotic value of 20 corr-liters per discharge. By summing the gas input required for the entire sequence and subtracting the minimum (asymptotic) gas fueling of 20 torr-liters per discharge, we obtained a measurement of $=100$ torr-liters for the pumping capacity of the conditioned bumper limiter for ohmic plasma.

\subsection{Discussion}

It is evident from the density decay time constant, edge neutral pressure, and Da emission measurements that exposure of the bumper limiter to an extended series of low density discharges significantly reduces the recycling. The low density limit for these conditioning digchargeg, which are fueled with the minimal amount of gas to satisfy discharge breakdown, was reduced by approximately a factor of two. Subsequent conditioning sequences, which followed exposure of the limiter to high density gas- and pellet-fueled discharges, showed reductions by factors of three in the densisy 1 imit.

A detailed explanation of the relationship between reduced recycling and the low densicy discharge conditioning process is a subject of current study. Two models are digcussed here which account for the observed drop in recycling as the result of a pumping capability induced in the graphite limiter material by the conditioning discharges: (1) a depletion model based on deuterium adsorptior-desorption in the near surface region of the bumper 
limiter, and (2) a codeposition model based on deuterium adsorption in carbon films formed by material sputtered from the limiter.

The hydrogenic retention property of graphites, such as the TETR liniter material, is the subject of recent investigation [3-7,18-19]. For AXF-5Q (and similar) graphites at room temperature the saturation concentration, $D / C$, is appraximately 0.4 , and this ligiting concentration falls rapidly with increasing cemperature $[18,19]$. Below the saturation concentration, incident deuterium that penetrates the lattice is retained (i.e., pumped) at low graphite temperatures. The saturation volume and, hence, the pumping capacity depend on the implantation depth of the incident deuterium. For typical edge electron temperatures $\left(T_{e}(a)=75\right.$ eV estimated for TFTR low density discharges [20], the impacting ion energy of deuterium incident onto the 1 imiter is of the order of $\sim 200 \mathrm{eV}$, and the implantation depth of such particles is $\sim 10 \mathrm{~nm}$ $[21]$.

The first model of graphite limiter pumping explains the pumping effect simply as the result of deuterium retention by a nonsaturated near-surface regiun of the limiter. The active volume is the product of the scrape-off area of the limiter and the implantation depth. In the unconditioned state this implantation volune of the bumper limiter is saturated; therefore, the pumping capacity is zero and the limicer recycling coefficient is close to unity.

The conditioning process with the low density discharges partially depletes the hydrogen within the implantation volume by an ion impact desorption process. The incident particle which initiates the desorption process can be a hydrogenic ion, helium ion, or carbon ion since spectroscopic analysis and the measured $z_{\text {eff }}(5-6)$ of the conditioning discharges indicate that both the helium- and deuterium-initiated discharges have significant carbon ion content. 
The replacement of an implanted hydrogenic species in carbon by a different isotope is well documented in the literature [22]. The hyarogen isotope exchange process can be optimized by matching the implantation range of the incident particle with the depth of the implanted isotope by adjugtment of the incident particle velocity. Such one-for-ore interchangs of hydrngen isotopes cannot regult in a net depletion of the saturated layer; however, the helium flux in the helium-fueled discharges and the carbon flux in both types of conditioning discharges (helium or deuterium initiated) are expected to cause a net depletion of hydrogenic species [23].

Recently, Wampler, Doyle, and Brice [24] have measured the rate of deuterium depletion in carbon by helium and carbon ion-induced descrption. Using graphite samples that have been implanted to saturation by exposure to a $10^{17} \mathrm{~cm}^{-2}$ fluence of $300 \mathrm{eV}$ deuterium ions, Wampler et al. [24] measured a depletion of $\sim 12 \pi$ of the implanted deuterius sfter a fluence of $10^{16} \mathrm{~cm}^{-3}$, $600 \mathrm{eV}$ He ions, and a deplecion of $=33 \%$ of the implanted deuterium after a Eluence of $10^{16} \mathrm{~cm}^{2}, 3 \mathrm{keV} \mathrm{C}^{+}$ions (Fig. 11). These data indicate that carbn! ions are more efficient in releasing deuterium from the saturated surface of graphite, and thus ion-induced desorption by carbon ions probably plays the dominant role in the limiter conditioning process.

This depletion mudel of graphite pumping accounts for the obgervec transient nature of the reduction in recycling and our inability to observe strong pumpinis effects with plasma operation on the TFTR moveable 1 imiter. The pumping capacity of the depieted layer on the bumper liniter is limiled, and is estimated to be the same as the gas loading ( 10 o torr liters) of ten fiducial density discharges, which was demonstrated to saturate the pumping effect. 
Limiter pumping, as manifest by less than unity recycling, has not been observed with plasma operation on the TFia moveabla limi-er: We ladue not observed values of the densizy decay constant. ${ }^{7} p$ less then 8 s after conditioning the moveable limiter sith low density discharges. There are several reasons to expect the recycling on the moveable liniter to be near unity during much of the steady-stace portion of a high power discharge. The smaller limicer scrape-uff area $\left(\sim 0.4 \mathrm{~m}^{2}\right)$, which is an order of magnitude smaller than the bumper limiter scrapt-off area $\left(-5 \mathrm{~m}^{2}\right)$, results in a smaller saturation capacity. The higher bulk limiter temperature (< $800^{\circ} \mathrm{C}$ for ohmic discharges on the moveable imiter, compared to $<60^{\circ} \mathrm{C}$ for she bumper limiter) results in a further reduction of the saturation capucity. Using the 3-b neutral transport code, DEGAS [16], Heifetz et al. [25,26] have calculated that the recycling coefficient on the moveable limiter reaches unity in less than 0.5 s after the initiation of a typical TrTR ohmically heaced discharge.

As seen with the bumper limiter conditioning, we have obgerved that exposure of the moveable limiter to a low density ronditioning discharge sequence does remova gas from the limiter and lower the minimum achievable plasma density. In fact, this conditioning procedure was first attempted in TFTR with the moveable limiter and led to the discovery of the enhanced confinement mode [10]. The apparent differences in limiter recycling effects observed with operation on the moveable or bumper limiter, and the relationship between limiter conditioning and the enhanced confinement discharges are active copics for furcher investigation.

A second model for graphite limiter pumping atributes the pumping effect to adsorption in a carbon film sputtered onto the vessel surfaces by the conditioning discharges (Wilson and Hsu [7] and winter [27]). In-situ observations and measurements in tokamaks with graphite limiters $[2,8,27-29\}$, 
and laboratory measurements with hydrogenic glow discharges with graphite electrodes $[5,6]$ show that significant quantities of carbon can be sputtered from the bulk graphite and redeposited as a carbonaceous film on vessel surfaces. Sputtered carbon can also be redeposited onto lower particle flux regions of the limiter. The sputcering processes in the conditioning discharges by the carbon and helium ions are more efficient than sputtering by deuterium ions. At an impacting ion energy of $300 \mathrm{eV}$ the physical sputcering coefficients for $\mathrm{C}^{+}, \mathrm{He}^{+}$, and $\mathrm{D}^{+}$are $0.23,0.077$, and 0.024 , respectively, $[30,31]$ and the actual physically sputtered flux in TETR should show a larger variation at a given sheath petential because of the probable multiply charged states of $\mathrm{He}\left(\mathrm{He}^{++}\right)$and $\mathrm{C}(\mathrm{CIV}-\mathrm{CV})$. At higher limiter temperatures (such as with the case of moveable limiter operation in TFTR erosion yialds by hydrogenic species can be enhanced by chemical sputtering or radiationenhanced sublimation [32].

To test the plausibility of this codeposition model for the pumping effects observed in TFTR, we estimated the capacity of the redeposited films to pump hydrogenic species using data from wall samples that were removed from the TFTR vessel in March 1986. These wall samples were distributed poloidally and toroidally and were exposed to the initial vacuum vessel conditioning at the beginning of the run [8], followed by $\sim 1770 \mathrm{high}$ power, deuterium-fueled discharges. Net deposition of a carbonaceous film was measured on all the samples, with a composition: $80-90$ at.Z C, 6-10 at.Z $0,1-6$ at.Z $D$, and 1 at. $z$ metals. The average carbon deposition $=3.5 \times 10^{18} \mathrm{~cm}^{-2}$, and the average $D$ deposition was $1.3 \times 10^{17} \mathrm{~cm}^{-2}$, yieldine an approximate $4 \%$ saturation of the film. If we multiply the average sample loading of $D$ per discharge $\left(7.3 \times 10^{13} \mathrm{~cm}^{-2}\right)$ by the vessel wall area $\left(\sim 200 \mathrm{~m}^{2}\right)$, the observed wall loading corresponds to a wall pumping of $D$ per discharge of $1.5 \times 10^{20}$ 
( $=5$ torr-1iters). Considering the crudity of these numerical estimates and the fact that the deposited film is capable of roughly a factor of ten larger hydrogenic loading, we cannot discount the codeposition model as a contributing source of wall and/or limiter pumping in TFTR. However, preliminary results from a 3-D particle transport calculation of a bumper limiter discharge [26] indicace that only $1-5 \%$ of the total hydrogenic flux impacts wall areas beyond the bumper limiter. Therefore, even chough the deposited films on the vessel wall may have the capacity for pumping, our initial estimate of the incident hydrogenic flux is too low to account for the observed pumping effects.

\subsection{Conclusions}

We have described the pumping effects observed with operation of the toroidal graphite bumper limiter in TFTR. The pumping effects are induced by conditioning the limiter with a series of Low density helium- or deuteriuminitiated discharges. The following pumping effects are observed to occur with conditioning of the bumper limiter: (1) During gas-fueled ohmic discharges, the effective particle confinement time, $\tau_{p}^{*}$, decreases from $\tau_{p}^{*}>$ $10 \mathrm{~s}$ to a minimum value of $\tau_{p}{ }^{*}=0.15 \mathrm{~s}$; this decrease in $\tau_{p}{ }^{*}$ corresponds to a decrease in global recycling from $R=1$ to $R \leq 0.5 ;$ (2) the minimum plasma density sustained at low plagma currents ( $1 \mathrm{MA}$ ) decreases by a factor of two; (3) the edge neutral pressure and recycling flux during neutral beat fueling decreases by almost an order of magnitude. Subsequent neutral beam heating experiments into low density target plasmas with a conditioned (i.e., low recycling) limiter have shown energy confinement times which are enhanced by a factor of two over previous values obtained with an unconditioned (i.e., high recycling) limiter [10-12]. 
We have proposed two mechanisms for the observed pumping fifects: (1) a depletion model based on pumping of the hydrogenic species in the near-surface region of the bumper limiter, and (2) a codeposition model based on pumping by carbon films sputtered from the limicer by the conditioning. Considering that the pumping effects have been observed only with plasma operation on the large area bumper limiter (which operates near $60^{\circ} \mathrm{C}$ ) and that the pumping capacity $(=100$ tartiters $)$ is consistent with the hydrogenic capacity of the depletion layer, we favor the depletion model as the primary cause of the pumping effects observed in TFTR.

\section{Acknowledgements}

We acknowledge D.K. Owens and $M$. Bell for their help in developing the concept for helium conditioning discharges. It $\geq$ use of low densiig deuterium conditioning discharges was first explored on the moveable limiter by $\mathrm{J}$. Strachan. The authors wish to thank our colleagues at Sandia National Laboratory, D. Brice, B.L. Doyle, W.L. Hsu, A. Pontau, H. Haøpler, and K. Wilson for their contributions to this study, and for providing the date of Ref. 24 prior to publication. The authers thank R. Hawryluk, D. Manos, F. Wagner, and M. Zarnstorff for useful discussions and participation in the experimental studieg. This work was supported by US DOE Contract No. DE-ACO276-CHO3073. 
References

[1] L. Sevier, M.F. Ho, J. Citrolo, J. Bialek, D. Wiessenburger, and I. Zatz, Proc. 10th Symp. on Fusion Energy, Philadelphia 1983 (IEEE, NY 1984) PP. 1072-1076.

[2] A.E. Pontau, W.R. Wampler, B.E. Millg, B.L. Doyle, A.F. Wright et al., J. Vac. Sci. Tei 101. A4 (1986) 1193.

[3] R.A. Causey, M.I. Bagkes, and K.L. Wilson, J. Vac. Sci. Technol. A4 (1986) 1189.

[4] R.S. Strehlow, J, Vac. Sci, Technol. A4 (1986) 1183.

[5] W.L. Hsu and R.A. Causey, Proc. 10th Intern. Vacuum Congress and 33td National Symp. of the American Vacuum Society, Baltimore, October 1986, J. Vac. Sci. Technol. A. (in press).

[6] R.A. Langley, op. cit.

[?] K.L. Wilson and W.L. Hsu, J. NucL. Mater. 145/147 (1987) 121.

[8] H.F。 Dylla and the TFTR Team, J. Nucl. Mater. 145/147 (1987) 48.

[9] A.E. Pontau and D.H. Morse, J. Nucl. Mater. 141/143 (1986) 124.

[10] J.ذ. Strachan, M. Bitter, A.T. Ramsey, M,C. Zarnstorff, V. Arunasalam et al., Phys. Rev. Letr. 58 No. 10 (1987) 1004.

[11] R.J. Hawryluk, V. Arunasalam, M.G. Bell, M. Bitter, W.R. Blanchard et al., Prac. 11th Inters. Conf, an Plasma Physics and Contr. Nucl. Fugion Research, Kyoto, November 1986 (IAEA, Vienna) paper no. IAEA-CN47/A-I-3.

[12] R.J. Goldston, op. cit., paper no. IAEA-CN-47/A-II-1.

[13] M. Shimada, A.T. Ramsey, D.K. Owens, H.F. Dylla, R.V. Budry, et al., J. Nucl. Mater. 145/147 (1987) 544 .

[14] A.T. Ramsey and S.L. Turner, Rev, Sci. Instrum. (in press)

[15] K.W. Hill, V. Arunasalam, M.G. Bell, M. Bitter, W.R. Blanchard et al., Proc, Ilch Intern. Conf. on Plasma Phys, and Contr. Mucl. Fusion Research, Kyoto, November 1986 (IAEA, Vienna) paper no. IAEA-CN-47/A-IV2 .

[16] D.B. Heifetz, J. Comput. Phys. 46 (1982) 309.

[17] P.H. LaMarche, H.F. Dyl la, D.K. Owens, N.D. Arnold, W.J. Hojsak et al., Rev, Sci. Instrum. 56 (1985) 981 .

[18] B.L. Doyle, W.R. Wampler, and D.K. Brice, J. Nucl. Mater. 103/104 (1981) 513. 
[19] M. Braun and B. Emmoth, J. Nucl. Mater. 128/129 (1984) 657.

[20] R.V. Budny, D.B. Heifetz, S. Kilpatrick, D. Manos, D.K. Owens et al.. J. Nucl. Mater. 145/147 (1987) 245 .

[21] Calculated from TRIM 86 computer code (D.K. Brice. Sandia National Laboratories, 1986).

[22] D.K. Brice, B.L. Doyle, and W.R. Wamplet, J. Nucl. Mater. 111/112 (1982) 598.

[23] W.R. Wampler and S.M. Myers, J. Nucl. Macer. 111/112 (1982) 616.

[24] W.R. Wampler, B.L. Doyle, and D.K. Brice, (privace communication).

[25] D.B. Heifetz, H.F. Dylla, M. Ulrickson and M.I. Baskes, J. Nucl. Mater. $145 / 147(1987) 326$.

[26] D.B. Heifetz, H.F. Dylla, M. Ulrickson, and M.I. Baskes, Bull. Am. Phys. Soc. 31 (1986) 1448.

[27] J. Winter, Proc. 10th In:ern. Vac. Congress and 33rd National Symp. Am. Vac. Soc., J. Vac. Sci. Technol. (in press).

[28] J.P. Coad, B.J. Davies, G.J. Edge, G.M. McCracken, and J. von Seggern, J. Nucl. Mater. $145 / 147(1987) 747$.

[29] H.F. Dylla, M.A. Ulrickson, P.H.Lakarche, D.K. Owens, and B.L. Doyle, J. Vac. Sci. Technol. A3 (1985) 1105.

[30] E. Hechtl, J. Bohdansky, and J. Roth, J. Nucl. Mater 103/104 (1981) 333.

[31] J. Roth, J. Bohdansky and W. Ottenberger, "Data on Low Energy Light Ion Sputerering," Report IPP 9/26 (MaY, 1979) Max-Planck-Institut für Plasmaphysik, Garching.

[32] J. Roth in Phygics of Plasma-Wall Interactions in Concrolled Fusion, D.E. Post and R. Behrisch, eds. (Plenum, New York, 1986) pp, 389-412.

[33] B.L. Doyle, W.R. Wampler, D.K.'Brice, and S.T. Picraux, J. Nucl. Mater. 93/94 (1980) 551. .

[34] P.C. Efthimion, N.L. Bretz, M.G. Bell, M. Bitter, W.R. Blanchard, Proc. 10th Intern. Conf. on Plasma Phys, and Contr. Nucl. Fusion Research London, UK September 1984 (IAEA, London) (IAEA, Vienna, Austria, 1985), Vol, 1, Pp. 29-54. 


\section{Figure Captions}

Fig. I Plasma density and gas input behavior for three operational cases in TFTR (a) standard conditions on moveable limiter or bumper limiter when recycling is close to one and the density decay constant ( ${ }^{k}$ ) is $>10 \mathrm{~s}$. (b) $1.4 \mathrm{MA}$ discharge on the bumper 1 imiter $(\mathrm{R} / \mathrm{a}=2.45$ m/ $/ 0.80 \mathrm{~m}$ ) after the initial conditionirg with ten low density He discharges. (c) $0.8 \mathrm{MA}$ discharge on bumper limicer after extensive condicioning showing the lowest observed value of $\tau_{p}{ }^{*}=0.15 \mathrm{~s}(\mathrm{~d})$.

Fig. 2 Change in the line-averaged plasma density of 0.8 MA deuteriun-fueled conditioning digcharges. The discharges were fueled only with a small ( 3 torr-liter) gas fill prior to discharge initiation. During the breaks in the shot number sequence (r-axis), neutral-beamfueled discharges were made to test the level of conditioning.

Fig. 3 Change in the line-averaged plasma densicy of $0.8 \mathrm{MA}$ (a) and $1.4 \mathrm{KA}$ (b) helium-fueled conditioning discharges. The discharges were fueled with a 2 torr-liter prefill of the torus.

Fig. 4 Change in the line-averaged plasma density of $0.8 \mathrm{MA}$ deuterium-fueled discharges (prefill fueling only) over a 1000-ghot sequence which spans conditioning sequences shown in Figs. 2 and 3.

Fig. 5 Reduction in brigntnegs of the $\mathrm{D}_{\beta}$ emission and line-averaged plasma density during a sequence of 1.4 MA He conditioning discharges. 
Eig: 6 Change in the density decay constant $\left(\tau_{p}^{\stackrel{*}{*}}\right)$ and computed value of the global recycling coefficient $(R)$ over a 100-shot sequence which spans the conditioning sequence shown in Figs. 2 and 3 . These measurements were made using fiducial discharges that were interspersed within the conditioning sequence. The plasma density was programed to $\vec{n}_{e}=$ $1.25 \times 10^{19} \mathrm{~m}^{-3}$ prior to interruption of the deuterium gas input to allow the density to decay.

Fig. 7 Particle confinement time $\left(\tau_{p}\right)$ as a function of line-averaged piasma density for $0.8 \mathrm{MA}$ ohmic discharges on the bumper limiter. The values of $\tau_{p}$ were derived from absolute Da emission measurements (see [ext). For comparison, values of the global energy confinement time, $\tau_{E}(a)$, caiculated according to the description in Ref. 34 are also plotied.

Fig. 8 Change in the edge neutral pressure and Da emisgion over the conditioning sequence shown in Figs. 2 and 3 . These measurements were made at the torus outer midplane during the plasma density plateau of the fiducial discharges described in Fig. 6. The error bars in the pregsure data are indicative of the noise level of the measurements.

Fig. 9 Time dependence of the edge neutral pressure, plasma density, and required gas input for fiducial discharges at the beginning $(a, b)$ and end (c,d) of the conditioning sequence shown in Figs. 2 and 3. 
Fig. 10 Time dependence of the edge neutral pressure, plasma density, and required gas input for neutral-beam-fueled discharges at the

- beginning $(a, b)$ and and $(c, d)$ of the conditioning sequence shown in Figs, 2 and 3 .

Fig. 11 Ion-induced release of deuterium from graphite by $600 \mathrm{eV}$ He and 3.0 $\mathrm{keV} \mathrm{C}$ ions. The sample was saturated rith $300 \mathrm{eV}$ D prior to the release measurements. The $300 \mathrm{eV} H$ data points were calculated using the local mixing model [33]. These data provided courtesy of Wampler, Doyle, and Brice [24], Sandia National Laboratory. 

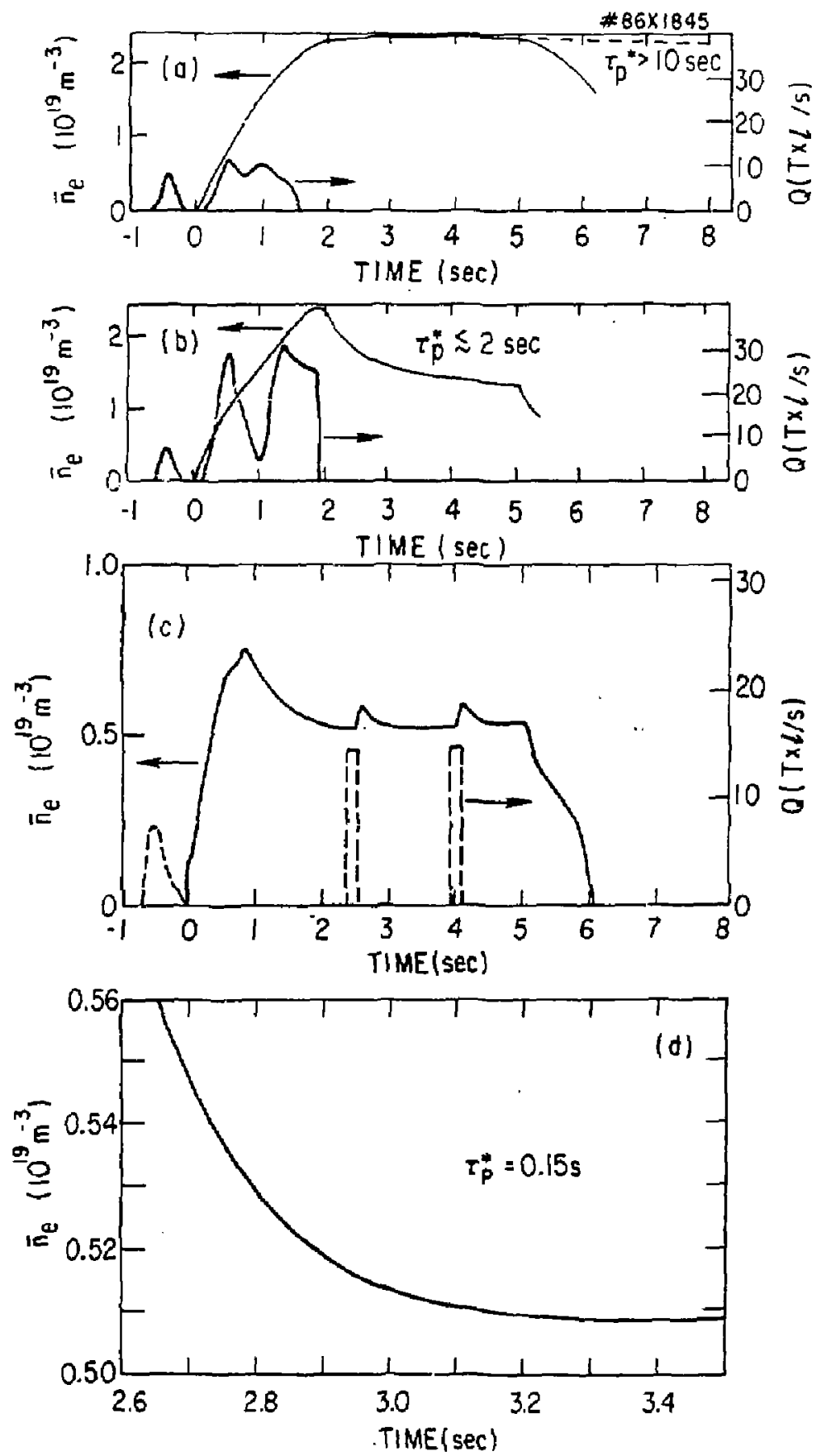

Fig. 1 


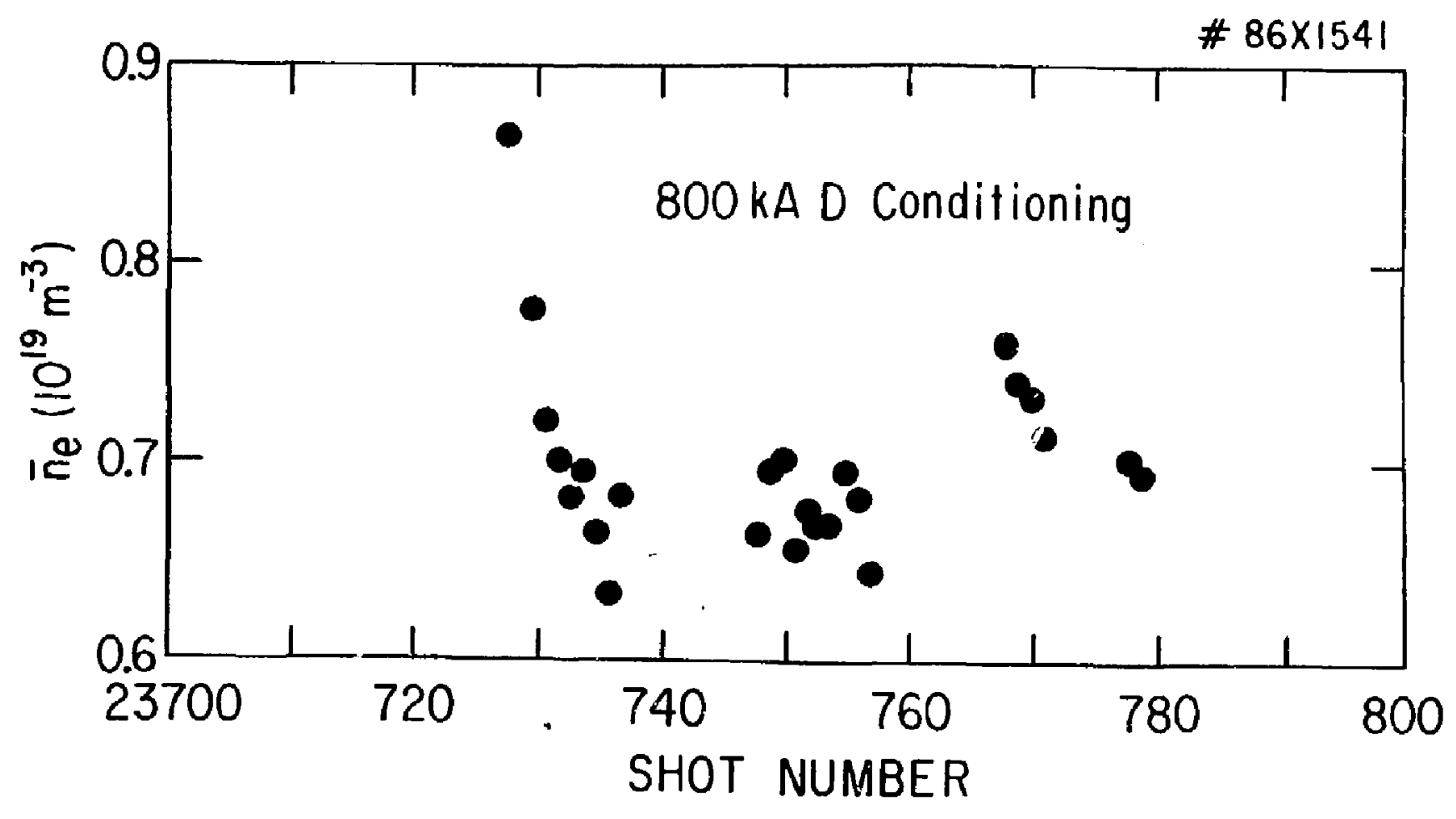



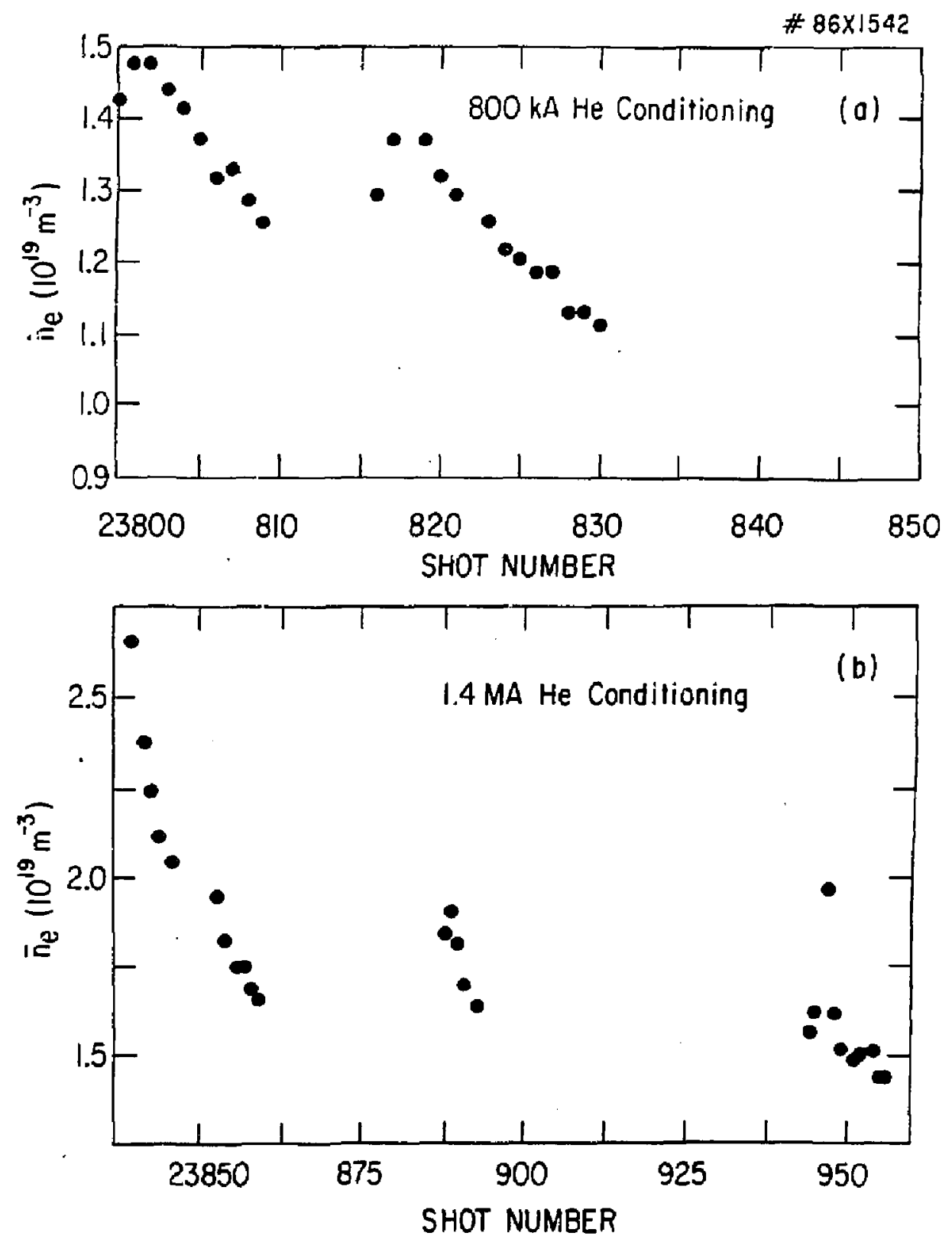

Fig: 3 


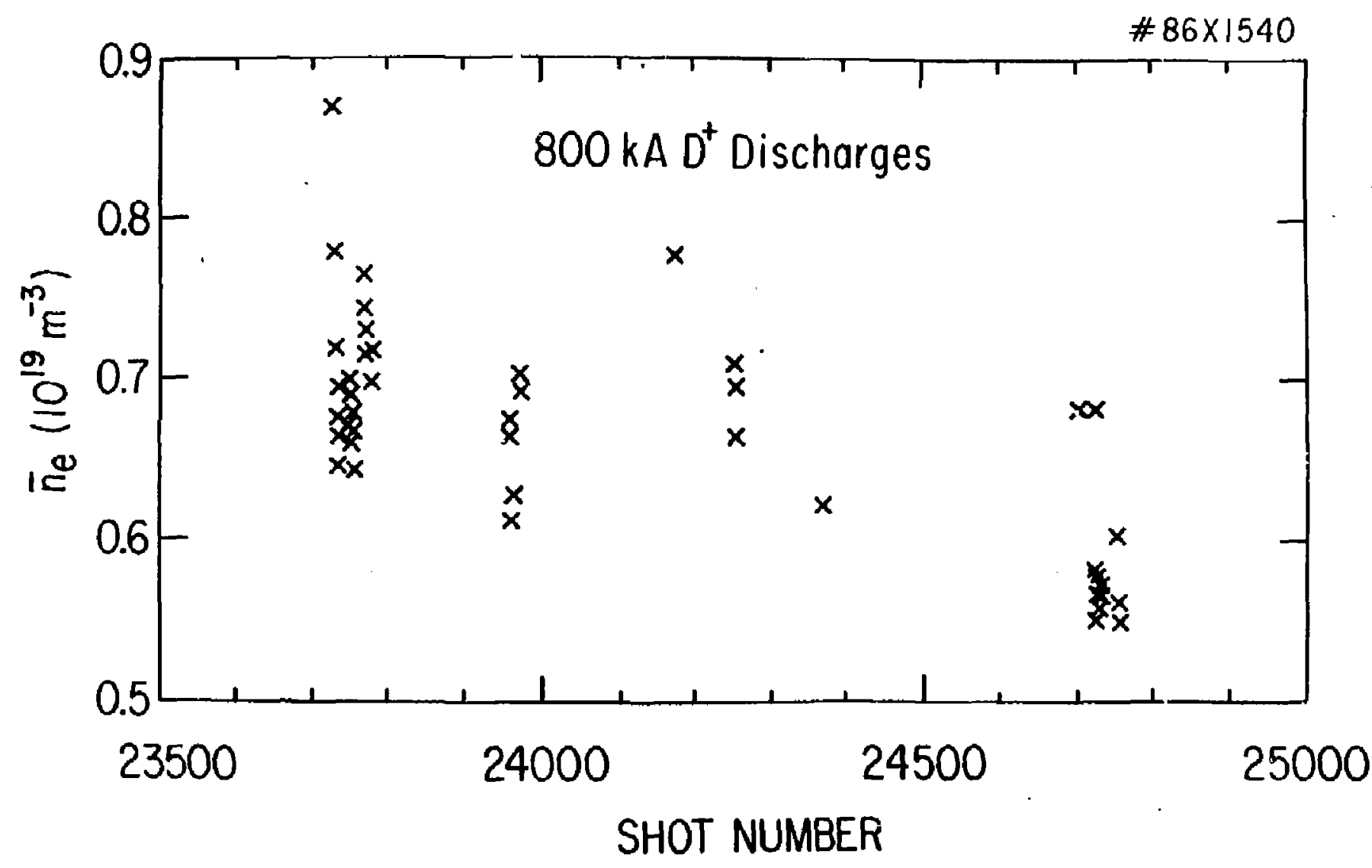

Fig. 4 


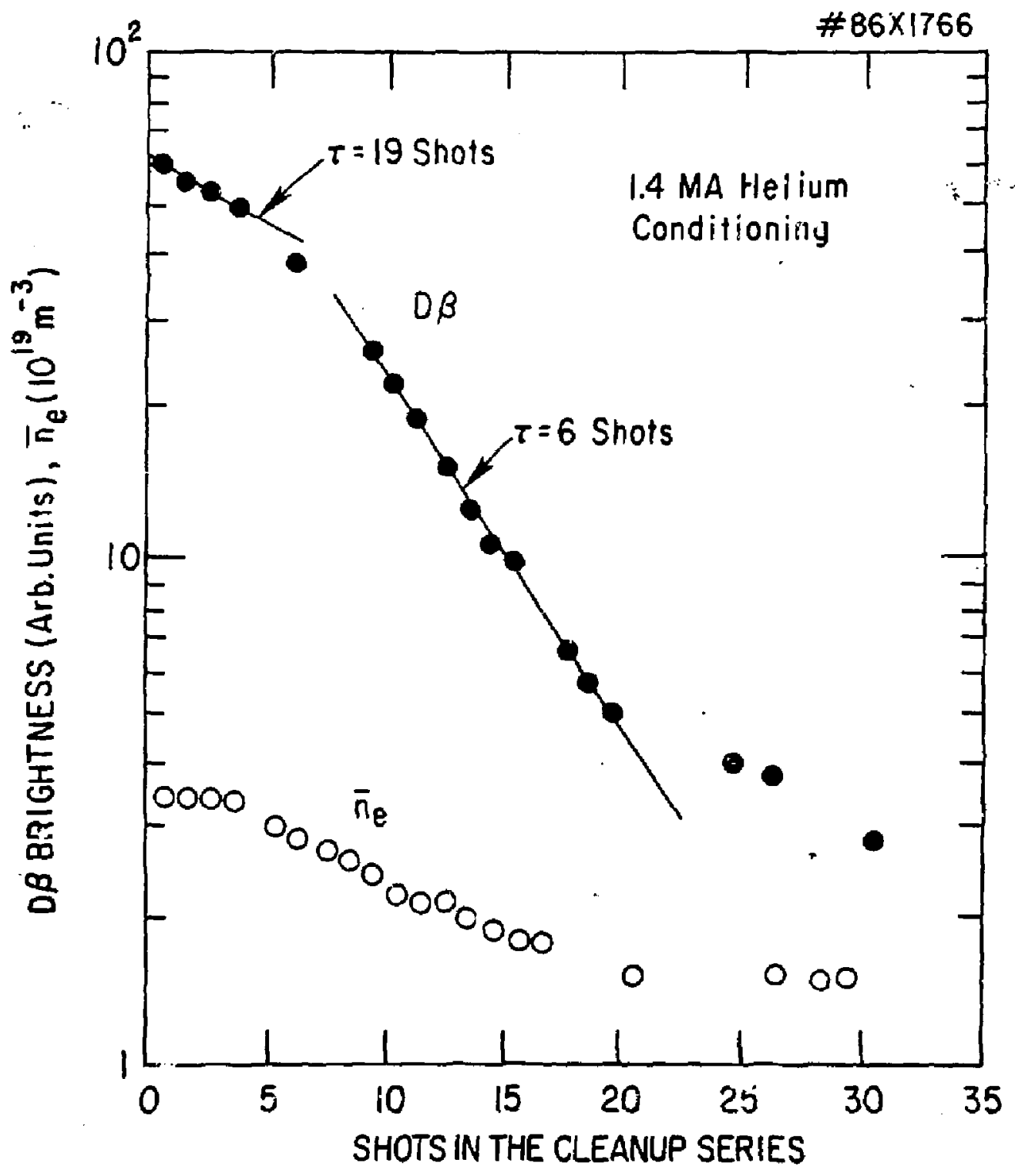

Fig. 5 


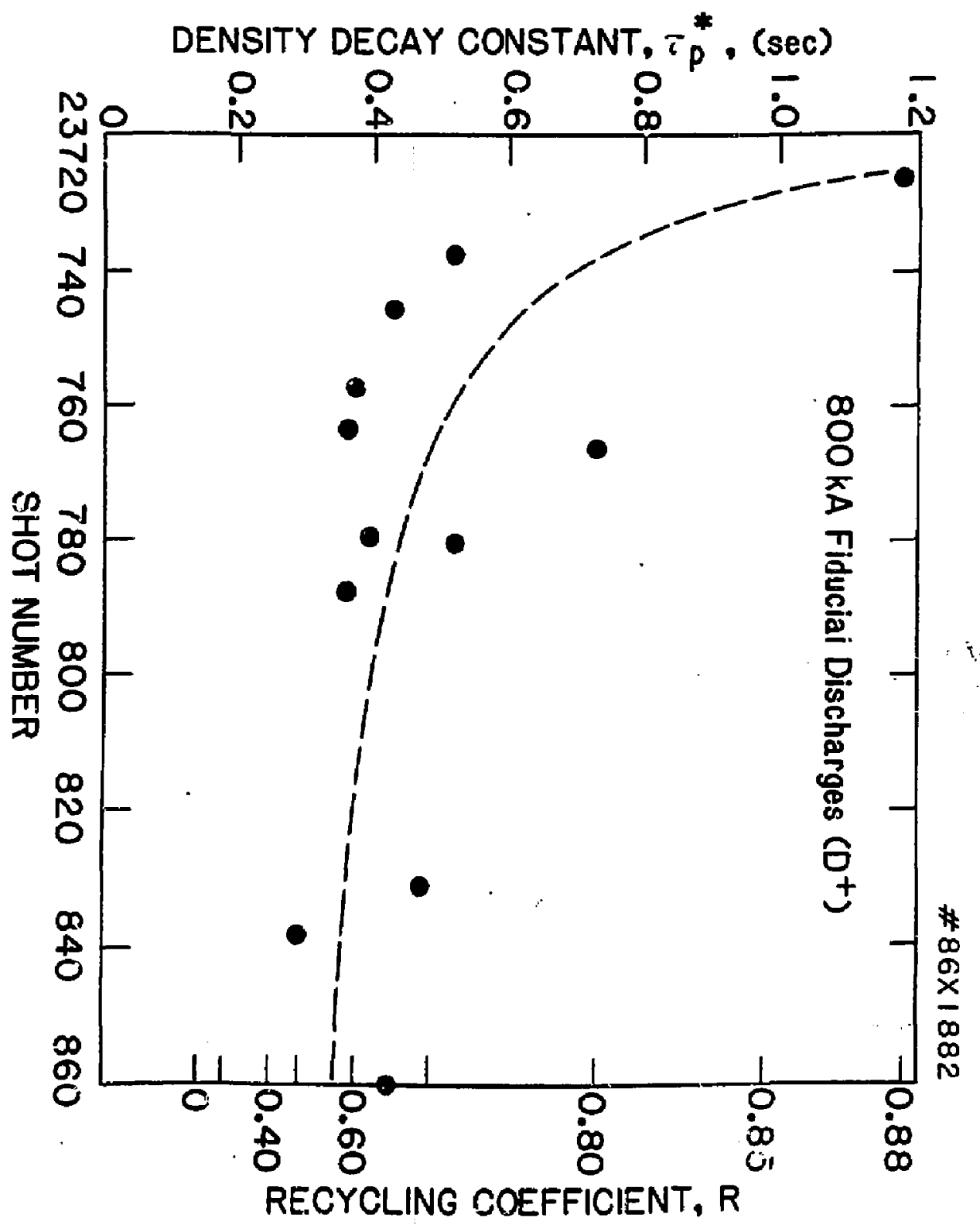




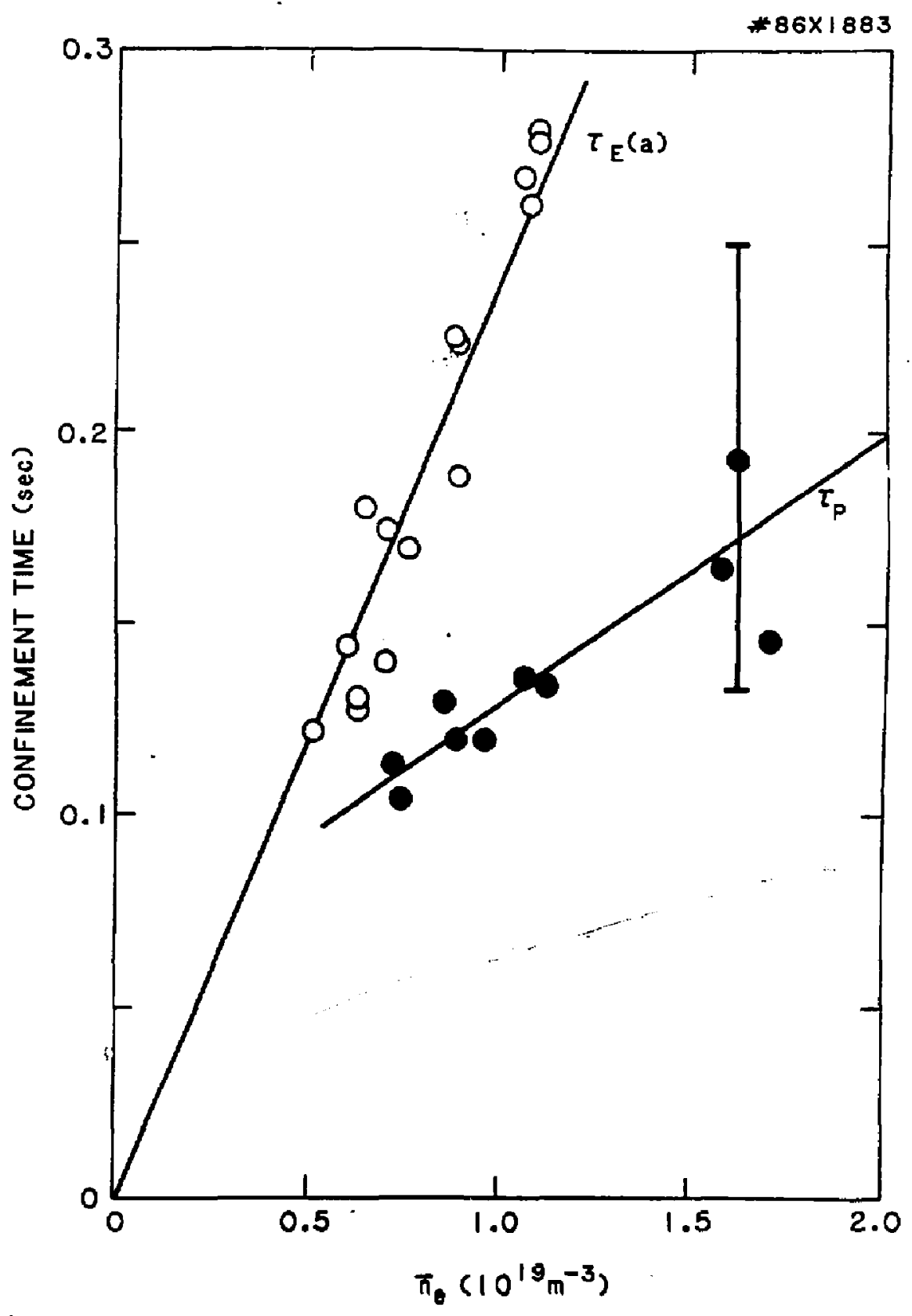

Fig. 7 


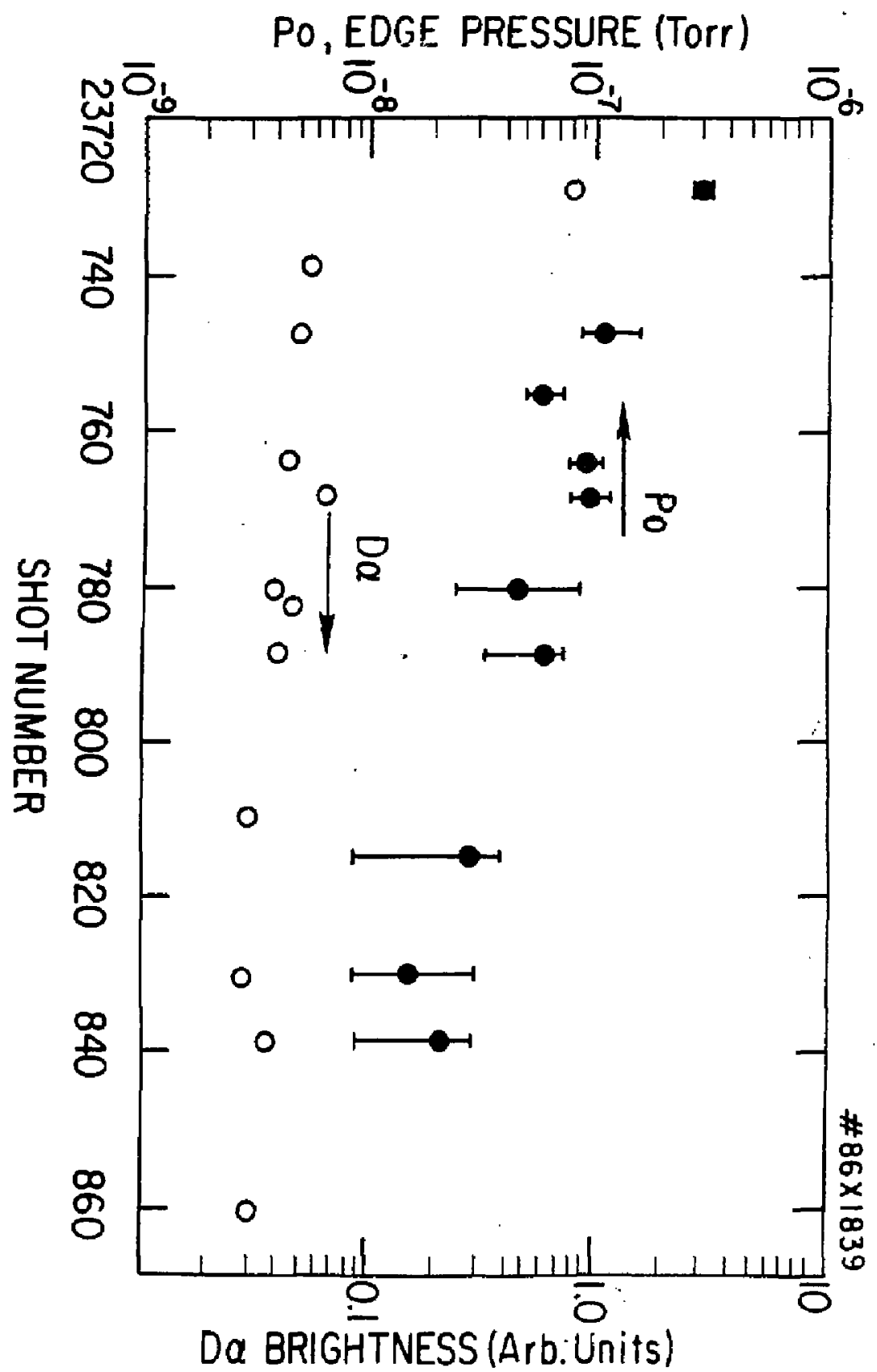



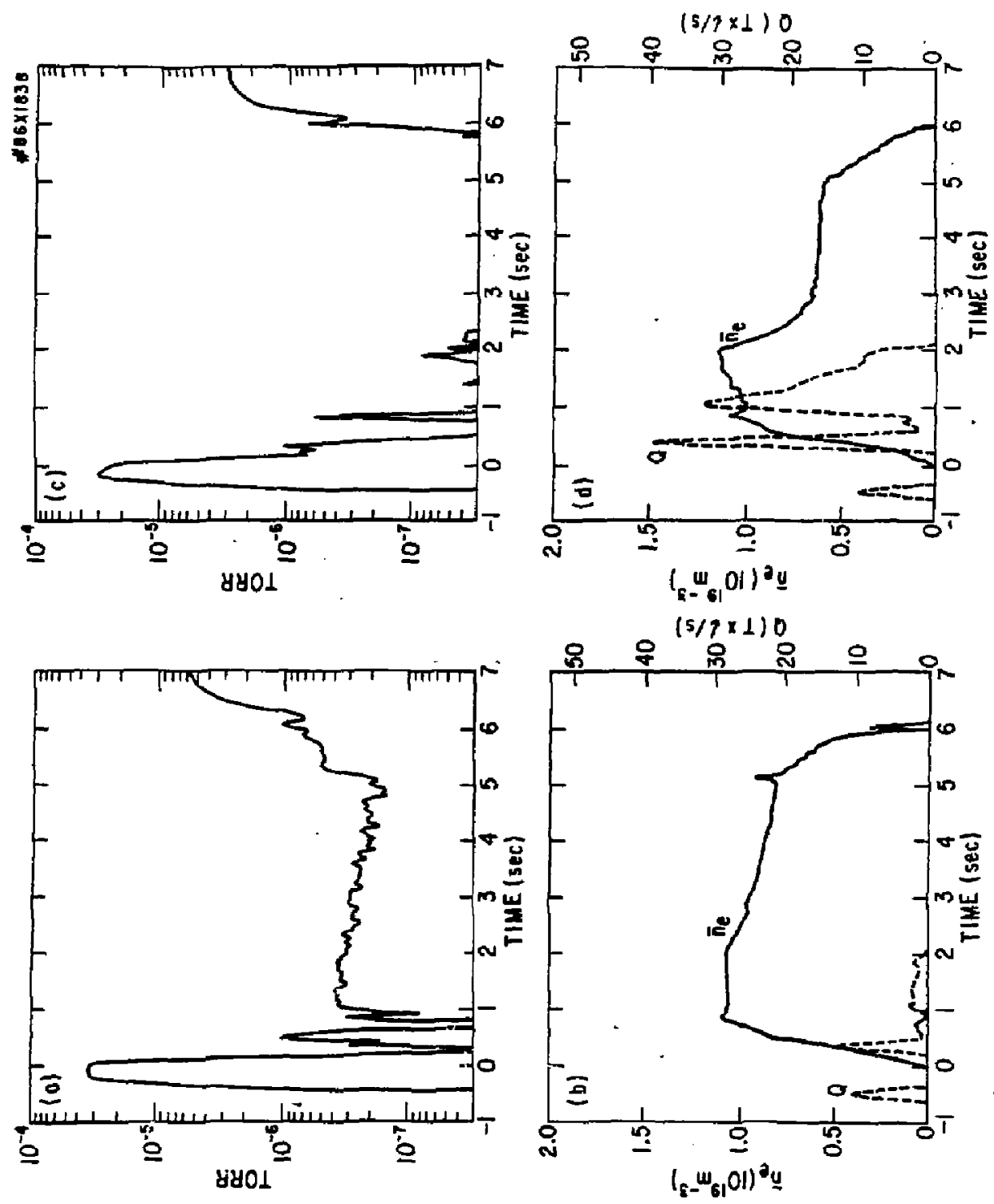

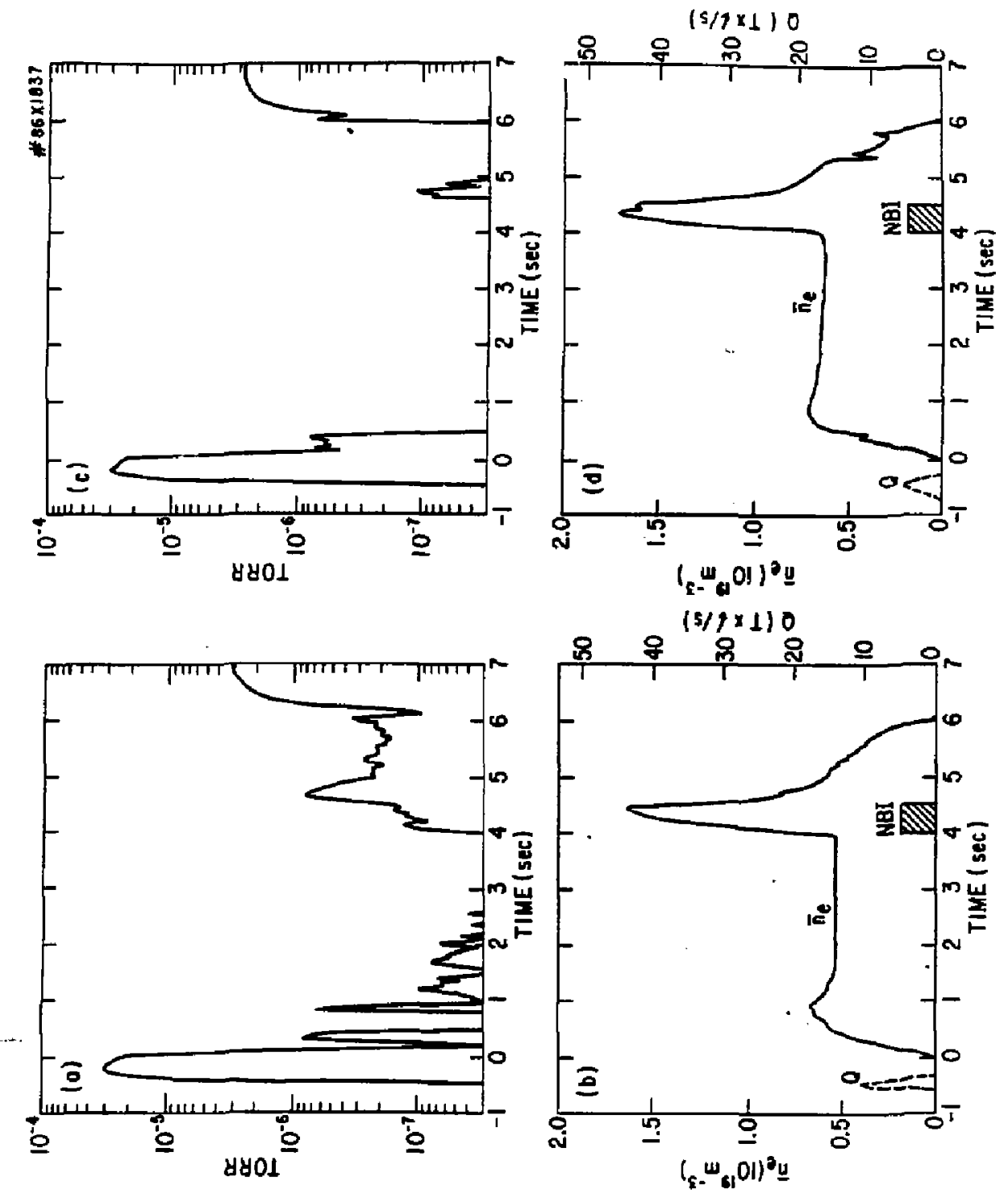


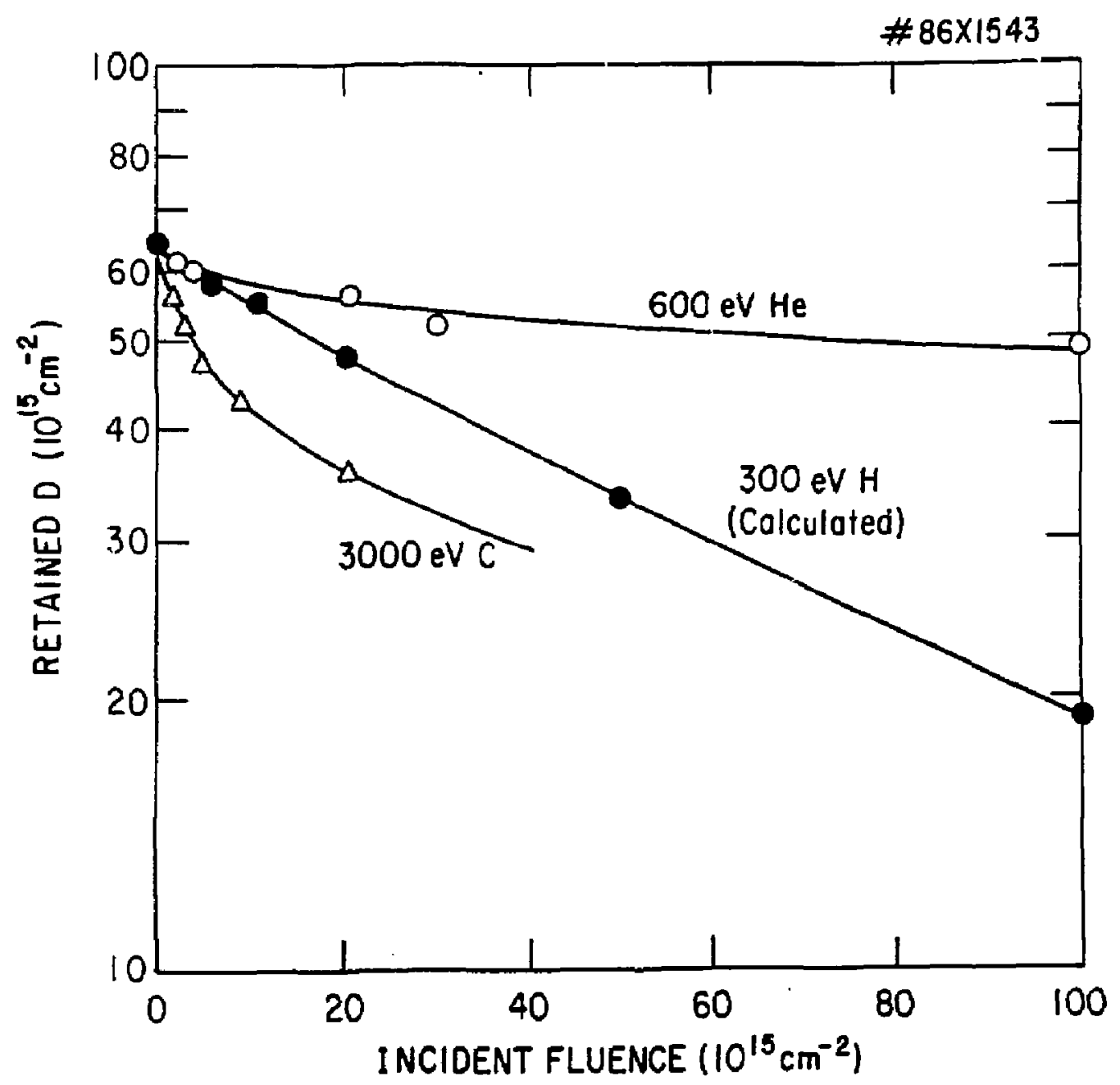

Fig. 11 
Or. Frank J. Paolonl, UnIu of wollongong, MUSTRALIA Prof. M.H. Bronnan, UnIv Sydney, AUSTRäis in

Plasme Reseerch Lab., Australlan Nat. Univ.., AUSTRALiA

Prof. I,R, Jonas, FIInders UnIV., AUSTRALIA

Prof. F. Cap, Inst Theo Phys, AUSTRIA

Prof. M. Helndler, Institut tur Theoretische Physlk, AUSTRIA

M. Goossens, Astronomisch InstItuut, BELGIUM

Eeole Royale Militalire, Lab de Phys Plasnos, BELGILA

Con. of European, Dg Xll fuslon Prog, BELGIUM

Prof. R. Bouslque, Loboratorilu voor Natuurkunde, BELGIUM

Dr. P.H. Sokonaka, UnIV Estadual, BRAZIL

Instituto Do Posquisas EspaclasI-INPE, ERMZIL

LIbrary, Atonle Energy of Canade Limited, CANADA

Or. M.P. Bachynski, MP Technologlos, InE., CNAPA

Or. H,M. Skarsgard, Jniv af Saskatchewan, CANADA

Or. H, Barnard, Univorsity of British Columbla, CANNA

Prot. 3. Telchmann, Unive of Montreal, CANADA

Prot. S,R, Sreanl:asan, Univorsity of Calgary, CANAOA

Prof. Tudor W. Johnstion, INRS-Energle, CANIOA

Or. C.R. James. UnIV. of Alberta, CANADA

Dr. Pater Lukac, Komenskeho Univ, CZEChOSLOVAKIA

The LIbrarlan, Culhem Laboratory, ENGLAwD

Mrs. S.A. HutchInson, JET LIbrary, EHGLND

C. Mouttet, Lab. de Physlque des Ml Ileux Ionlsés, FaAtCE

J. Radot, CEN/CADARACHE - Bat 506, FTAMCE

Cr. Tom Mual, Aeadeny Blbllographle, HONG KंONG

Proprint Librery, Cont Ros Inst Fhvs, HUMGARY

Dr. B. Desgupta, Saha Inst, IROIA

Dr. R.K. Chhojlanl, Ylkram UnIV. IFDIA

Dr. P. Kow, Institute for Plasma Research, IHDIA

Dr. PhIllip Rosanau, Israel Inst Tech, ISRAEL

Prof. S. Cuporman, Tol AvIv University. ISRAEL

Librarlan, In+'I Ctr Theo Phys, ITALY

Piof. G. RostognI, Univ DI Padove, ITALY

Mlss Clelis On Polo, Assoc EURATOH-ENEA, ITALY

Blblloteca, dol ONR EURATOA, ITALY

Dr. H. Yamoto, Toshiba Res I Dev, JNeN

Prof. I. Kawakal, AtomIc Energy Res. Institute, JAPAN

Prof. Kyojl NIstikawa, UnlY of Hiroshlmo, JAPAW

Dirac. Dept, Lg. Tokamak Ras. JAERI, JAPAN

Prot. Satoshl Itoh, Kyushu University, JAPAH

Research Into Conter, Nagoya Unlversity, JPPAH

Prot, 5. Tonaka, Kyoto UniverstTy, JAPAN

LIbrary, Kyoto UnIversity, JAPA"

Prot. NobuyukI InOue, UnIverslty of Tokyo, JAPAN

S. Mor I, JAERI, JAPAN

MaH. KIn, Korea Advanced Energy Rescarch IAstitute, KOREA

Prof. D.1. Chol, Adr. Inst Sel \& Tech, KCrEA

Prof. B.S, LIley, Univarslty of Walkato, NEW ZEMLAND

Institute of Plosine Physlcs, PEOPLE'S REUBLIC Of CHINA

Librarian, Institute of Phys., PECPLE'S REPUBLIC Of CH!NA

Llbrory, Tsing Hua Ualvers' 'y, PECPLE's REUBLIC OF CHINA
Z. LI, Southrest Inst. Physles, PECPLE'S REPUBLIC OF CHINA Prot. J.A.C. Cabral, Inst Superlor Tecn, PORJUGAL

Or. Octoulan Petrus, AL I CUZA UnIversity, ROMANIA

Or. Jahan da Villliars, Plasma Physles, AEC, SO AFRICA

Prot. M.A, Hellberg, University of Natal, SO AFRICA

Fusion DIv. LIbrary, JEN, SPAIN

Dr. Lennart stenflo, UnIversity of UMEA, SWEDEN

Library, Royal Inst Toch, SWEDEN

Prof. Hans Wilhelmson, Chaliners Univ Taeh, SWEDEN

Centre Phys des Plesmas, Ecole Polyteen Fed, 5WITZERLAND

Bibllatheak, fom-l nst Voor PIasme-Fysles, THE NETHERLANDS

Dr. D,0. Ryutov, Slberlan Aced Sel, USSR

Dr. G.A. Ellsew, Kurchator Institute, USSR

Dr. $Y$, A, Glukhikh, Inst Eloctro-Physical, USSR

Or. Y.T. Tolok, Inst. Phys. Tech, USSR

Or, L,M. Kovelizhnykh, Institute Gen. Physles, USSR

Prof. T.J.H. Boyd, Univ college $N$ holes, wales

Nuelear Res. Establishment, Jullich Ltd., W. GERMANY

Blbllathak, Inst. Fur Plasmaforsehung, W. GERMANY

Or. K. Schindlar, Ruhr Ualversitrat. W. GERHANY

ASOEx Rooding Roh, IPP/Max-Planck-Instl tut fur

Plasmaphysik, W, GEReNANY

LI brarlan, Maxtfianck institut, W. GerkwiY

Prot. R.K. Janev, Inst Phys, YugosLavia 